\title{
Effects of the Patience Training Program on Patience and Well-Being Levels of University Students
}

\author{
Ayşe Eliüşük Bülbül ${ }^{1}$, Gökhan Izgar ${ }^{1}$ \\ ${ }^{1}$ Faculty of Ereğli Education, Necmettin Erbakan University, Turkey \\ Correspondence: Ayşe Eliüşük Bülbül, Necmettin Erbakan University, Faculty of Ereğli Education, Konya, Turkey.
}

Received: November 22, 2017

Accepted: December 25, 2017

Online Published: December 29, 2017

doi:10.11114/jets.v6i1.2900

URL: https://doi.org/10.11114/jets.v6i1.2900

\begin{abstract}
In this study, the effect of patience training on patience and well-being levels of university students was examined. The sample group of the study consisted of 1.2.3. and 4th grade students with a total of 30 students from Konya Necmettin Erbakan University, Ereğli Education Faculty. For the collection of data, the Patience Scale developed by Schnitker (2010) and adapted to Turkish by Eliüşük and Arslan (2016) and the PERMA Well-being Scale developed by Kern (2015) and adapted to Turkish by Eliüşük (2016) was used. The measuring tools were applied to the experimental and control groups three times; the first before, the second one week after the and third three months after the end of the application. In the study, a patience education training consisting of 10 sessions was applied to the experimental group. No training was given to the control group. The Mann-Whitney U test and the Wilcoxon tests were used in the analysis of the data. As a result of the analyzes made at the end of the practice; significant differences where observed in individuals patience levels but no meaningful changes were seen in the well-being levels.
\end{abstract}

Keywords: patience, education, well-being, patience training program

\section{Introduction}

Patience is seen as character strength and a desirable personality trait that encourages the development and well-being of humanity since a long time. Harned (1997) emphasized the importance of developing patience to ensure a good life. Although patience has been laid as an important feature for thousands of years, it has only recently attracted attention as an experimental research topic in psychology. So what is patience? Patience is in the most basic sense the tendency of a person to wait calmly in the face of disappointment, distress or suffering. Patience is used in various conditions and time intervals (Schnitker, 2010). It takes action (or not!) in more important and long-term situations, such as waiting in traffic, parenting, or struggling with a serious illness. Although patience is a component used in waiting situations, it is also used in situations that are not directly related to time (eg. dealing with a difficult person). Patience is often interpreted as a feature (eg. "he/she is a patient person") and may also describe a situation (eg, "waited patiently"). These two conceptualizations of patience are intertwined (those with high patience characteristics will experience more intense patience), so it is important to see both as meaningful features. Showing real patience is dependent on both behavioral (eg waiting) and emotional (eg showing less reaction than expected in a challenging situation or being non-reactive) components. Patience is a fairly new concept in psychology. The most basic meaning known is the tendency of the individual to wait calmly in the face of frustration, distress and pain (Schnitker, 2012). Mehriban (1999) defined patience as a limited determined and planned tendency, as well as a personality trait (people with patience tendencies can cope with difficulties and work until they reach their target). According to Parry \& Norling (2009)'s article; both patience and impatience are a value. According to Mc Clough, Tsang \& Emmons (2004); patience is seen as a typical tendency and situation. Given the prevalence of anticipatory and annoying stimuli in daily life, research is needed to examine individual differences in how people respond to these conditions in order to maximize human functioning (Schnitker \& Emmons, 2007). Schnitker (2010) mentions three types of patience. Patience in everyday life: is often described as waiting situations in everyday life. For example; traffic congestion, waiting for the bus or plane and waiting in line at the restaurant. Patience in life difficulties: is defined as the ability of a person to cope with any challenging experience, i.e. long-term diseases, financial problems, the attitude of mothers against their newborn babies. Interpersonal patience: is defined as the persons tolerance to other persons in social relationships, i.e. patience shown to challenging bosses, parents, adolescents or students. There are many studies showing that a lot of concepts are closely related to patience. It appears that there is a positive correlation with subjective well-being, positive coping, virtues and 
success. Patience is also closely related to life quality and well-being. Therefore, examining the relationship between patience and well-being will make a significant contribution to the literature (Schnitker \& Emmons, 2007). Before looking at the relationship between patience and well-being, it would be appropriate to make a definition of well-being first. It is a combination of feeling good and living in an effective way. Flourishing is synonymous with high level mental well-being and is a concrete example of mental health (Huppert 2009; Ryff and Singer 1998). Ryff (1989) created six dimensions of psychological well-being: self-determination, dominating the environment, personal development, positive relations, purpose of life and self-acceptance. According to Ryan and Deci (2001), well-being experiences arise from meeting of three basic psychological needs: self-determination, efficiency and relevance. According to Seligman (2002), the three basic elements of well-being are pleasure, engagement and meaning. In his last study, he introduced two further elements: relations and accomplishment (Forgeard et.al. 2011; Seligman 2011). According to Seligman, these five elements that make up the letters PERMA: positive emotion, engagement, relations, meaning, accomplishment; are "the best approach for persons own good" and define all together well-being. According to Seligman's (2011) model; positive emotions express hedonic feelings of happiness (eg, feeling fun, relaxed and joyfull). Engagement refers to the psychological commitment to activities or organizations. (Eg, involvement, care and feeling in life). Positive relationships; include feeling socially integrated, being cared for and supported by others, and being satisfied with one's social connections. Engagement (flow); full involvement and a feeling of full union with an activity, or an interaction that some define as the "flow" state (Csikszentmihalyi, 1991). Relations; social relations have positive effects on health and well-being of the individual and therefore are factors that affect the well-being of the individual. Meaning; a believe that one's life is precious and that it is connected to something superior to itself. Accomplishment; involves progressing towards goals, feeling the ability to perform daily activities, and feeling successful. Seligman (2011) argued that these five foundations, contributing to general well-being, can be independently defined and measured as important areas in which people are trying to reach for their own good.

\subsection{Literature Review}

When we look at the relationship between patience and well-being, we can find many examples in the literature. Schnitker \& Emmons (2007) found in their research that patient individuals experienced less depression. They found a positive relationship between patience and well-being. It also reflects the belief that patience is related with hedonic and eudenomic well-being, and that it is only about rising happiness up to the highest level and reducing negative feelings (Ryan \& Deci, 2001). Peterson \& Seligman (2001) stated that patience is associated with positive social characteristics and virtues, and patient individuals exhibit a more empathetic and more grateful attitude. Patience also includes strong virtues such as equality and justice. Patience protects hedonic well-being against emotions in stressful situations, helps people to cope with their frustrations in a more harmonious manner, and facilitates positive interpersonal interactions (Diener, Sapyta, \& Suh, 1998). Therefore, it can be said that patience influences indirectly hedonic well-being and therefore increases life satisfaction and positive feelings and makes it easier to reach the target. İt was seen that patient people have less negative affect, lower depression, less health problems, and an increased life satisfaction. Experimentally it has been found that there is a positive relationship between patience, optimism and hope. Patient individuals are in a rather fatalistic time perspective (Schnitker, 2012). If the life satisfaction of the patient people increases, the depression will decrease. The relationship between patience and other well-being indicators (depression, life satisfaction, loneliness and self-perception) is not significant (Schnitker \& Emmons, 2007). It has been suggested that patience is related to both pleasure and happiness. These two elements revealed the two fundamental distinctions of well-being. Physiological and experimental paradigms can be considered to understand a better life. Hedonism; according to Aristotle, Hobbs and Bentham, hedonism means minimizing negative emotions and maximizing happiness and comfort (Akt. Deci \& Ryan, 2001).

When we look at the relationship between hedonic well-being and patience; an increase of hedonic well-being were seen in patient persons, which showed that the patience increased satisfaction with positive emotions (Kahneman, Diener \& Schwartz, 1999). Patience was found to be related with good life and well-being in the positive relationships, purpose of life, self-acceptance, cognitive development and self-determination dimesions (Ryff \& Singer1988). Campton Smith, Cornish \& Qualls (1996) designed patience as a multidimensional model that includes pleasure and happiness as well as well-being. They found an average relationship between patience, happiness and well-being. Patience is explained by terms of happiness and hedonic well-being.

In our country, there are no studies available in order to increase patience or showing that patience is related to well-being. However, in view of the prevalence of annoying stimuli in everyday life, research is needed to examine individual differences in how people react to these conditions in order to maximize human functioning (Schnitker \& Emmons, 2007). For this reason, it is thought that this study, in which patience training is applied in order to increase patience, will contribute to the field.

The aim of this study is to investigate the effect of patience training program on patience. In addition, the effect on the 
well-being level of the patience education program was also examined. The hypothesis of this study is that "the individuals participating in the patience training will have a significant increase in patience and well-being levels compared to those who do not participate in these sessions, and this increase will continue in the follow-up measures to be made after 3 months".

\section{Method}

The research was organized as a pre-test-post-test and control group pattern. The experimental and control group consists of students who were studying in Necmettin Erbakan University Eregli Faculty of Education in 2016 - 2017 fall semester. İt has been announced to students of the Necmettin Erbakan University, Eregli Education Faculty that there will be carried out a research about patience and well-being. The participation in the study was on a voluntary basis. 50 of 100 students applied for the research and who had obtained similar average points from the Patience and PERMA Well-being Scales were selected. The students are divided into control and experimental groups, each with a total of twenty students. The experimental group received the patience training for 5 weeks. At the beginning of the training, 25 of them were in the control group and 25 of them were in the experimental group (Necmettin Erbakan University Ereğli Education Faculty students). Some students left the research for various causes and at the end of the training, the post-test was applied to 17 students from the control group and 17 students from the experimental group (Necmettin Erbakan University Ereğli Education Faculty students)

\begin{tabular}{|c|c|c|c|c|c|}
\hline & & Pre-test & & Post-test & Trail-test \\
\hline GD & $\mathrm{R}$ & O1.1. & $\mathrm{X}$ & O1.2. & $\mathrm{O} 3$ \\
\hline GK & $\mathrm{R}$ & O2.1. & & $\mathrm{O} 2.2$ & \\
\hline
\end{tabular}

GD: Experimental group which received Social Skill Training program

GK: Control group

R: Unbiased group assignment of subjects (Random)

O1.1. and O1.2.: Pre-test and post-test measurements of the experimental group

O2.1. and O2.2.: Pre-test and post-test measurements of the control group

O3: Trail test measurements

X: The independent variable applied to the experimental group (Patience Training Program)

The dependent variables of the research are the patience and well-being levels, the independent variable was the effect of the Patient Training Program on patience and well-being levels of university students.

\subsection{Experimental Procedures}

Process Path: At the beginning of the study, a literature search on the subject was made. Then a "Patience Training Program" was established in accordance with the relevant literature and patience scale items.

By creating the program for this purpose:

* Determining the outcomes and indicators related to the activities to be dealt with in order to gain patience and patience skills of eleven items in each sub-dimension of the patience scale,

* Deciding on effective learning methods which are considered suitable for use with patience skills that are thought to be improved,

* Determine the activities appropriate for the outcomes and indicators which improve the patience skills,

* The preparation of the daily training plans to be formed within the scope of activity-based patience training were followed.

* Then, the sample was determined and the experimental and control group was created from this selected sample.

The procedures applied to the experimental and control groups consist of three parts.

A. Pre-test: Patience and PERMA well-being scales were applied to the experimental and control groups.

B. The application of the patience training program to the experimental group: an activity based participatory patience training program was applied with a total of 110 activities for 5 weeks to the experimental group.

C. Post-test. After the implementation of the program, well-being and patience measures were applied to experimental and control groups again. The collected data were analyzed in the SPSS program.

\subsubsection{Preparation of the Patient Training Program}

The literature has been scanned first to put the Patient Training into a theoretical basis. The outcomes, goals and 
indicators were examined in the light of the items indicated in the Patience scale and the Patience Training was planned according to these goals and outcomes. Efforts have been made to ensure that the activities are supporting the patience skills and therefore also contribute positively to their well-being levels of the university students. At the same time it was taken care to create an activity-based training.

The faculty members of Konya Necmettin Erbakan University where asked for their opinions in order to enable whether this training is capable of improving university students patience skills and to determine whether it is capable to support their well-being. After the regulations made according to the opinions of the experts, the preliminary test of the "Patience Training" was made at Konya Necmettin Erbakan University and so the training program was finalized.

\subsubsection{Patience Training Program}

The main purpose of this study was to apply a patience training to the education faculty students and to examine the effects of this training. In order to achieve this goal, a training program with patience value were developed for the students. The objectives of this training program and the outcomes based on these goals are as follows:

Objective - 1: To be able to comprehend the place and importance of the patience value in human life.

Outcomes:

1. Define patience with its own expression.

2. Accept the importance of being patient.

3. Willing to be patient.

4. To be aware of the the negativities when he/she is not patient.

5. To be aware of the positive situations he/she will gain by being patient.

6. Explain the relations between patience and consequences of behavior.

Objective - 2: Be able to show patient behavior in daily life flow, in social relationships and in difficult situations

Outcomes:

1. Recognize situations that affect patientness in the flow of daily life.

2. Bring on suggestions about the necessity of being patient in daily life.

3. Explain the place and importance of patience in the flow of daily life.

4. Recognize situations that affect patience in social relations.

5. Discuss the place and importance of patience in social relations.

6. To recognize situations that affect patientness in difficult moments.

7. Discuss the necessity of being patient in difficult moments.

At the end of each session, the students were asked for their impressions and how they plan to apply them in their daily life. In addition, until the next session, the student is asked to use the outcomes gained in the session within the family, student residence, at school, in friendship etc. and this experineces were shared at the beginning of the next session.

\subsection{Data Collection Tools}

\subsubsection{Patience Scale}

The Patient scale was developed by Schnitker (2012) to determine the patience levels of individuals. There are three sub-dimensions on the scale: interpersonal, long-term (patience in life diffculties) and short-term (patience in daily life). There are a total of 11 items on the scale. İts a seven likert type scale. The internal consistency coefficient of the scale is 82. An adaptation study for the patience scale was carried out on a group of university students. For the language validity of the scale, the students studying in the English language teaching department made mutual translations (English-Turkish, Turkish-English) and a significant positive correlation was found between the scores obtained from the English and Turkish forms $(\mathrm{r}=.95, \mathrm{p}<.01 ; \mathrm{r}=.95, \mathrm{p}<.001)$. The 11-item, three-dimensional measuring instrument tested with DFA, appears to have an adequate index of goodness of fit $(\mathrm{x} 2 / \mathrm{sd}=100.96 / 41, \mathrm{p}=.00, \mathrm{RMSEA}=.076, \mathrm{CFI}$ $=.96, \mathrm{GFI}=.93, \mathrm{NNFI}=.94$ ).

As a result of the correlation analyzes made for the criterion validity of the patience scale; the students' scores on the patience scale were found to be positively correlated with self-recovery, social self-efficacy and the persistent sub-dimension of interpersonal problem solving. The internal consistency coefficient of the scale was $\alpha=.82$ and test retest correlation was calculated as .81 . As a result, the 11-item and three-dimensional measuring instrument has been made ready for use by researchers. 


\subsubsection{PERMA Well-Being Scale}

The PERMA Well-being Scale is a scale from Seligman (2013) which measures the the well being and is based on the theory that the well- being of individuals consists of five components. This scale was developed by Butler \& Kern (2015). The scale evaluates individuals' well-being in five dimensions: P: positive and negative emotions, E: Engagement, R: Relationships, M: Meaning and A: Accomplishment. The scale consists of 22 items and has a scoring interval from zero to ten. The internal consistency coefficient of the scale is .82. The adaptation study of the PERMA Well-being Scale was conducted on a group of university students. For the language validity of the scale, mutualy translations (English-Turkish, Turkish-English) were applied to students studying in the English language teaching department and positive correlations $(\mathrm{r}=.95, \mathrm{p}<01 ; \mathrm{r}=.95, \mathrm{p}<.01)$ were found between the scores obtained from the English and Turkish forms. The 23-item and 8-dimensional measurment tool tested with DFA appears to have adequate index of goodness of fit $(\mathrm{x} 2 / \mathrm{sd}=100.96 / 41, \mathrm{p}=.00$, RMSEA $=.076, \mathrm{CFI}=.96, \mathrm{GFI}=.93$, NNFI $=.94)$. As a result of the correlation analyzes made for criterion validity of the PERMA Well-being Scale; the scores students obtained from the patience scale were found to be positively significant related with the Subjective Well-Being Scale (Tuzgöl Erdost, 2005) and the Psychological Well-Being Scale (Telef, 2013). The internal consistency coefficient of the scale was $\alpha$ $=.82$ and test retest correlation was calculated as. 81. As a result, the 22-item and eight-dimensional measuring instrument was made ready for researchers to use.

\section{Findings}

As the number of samples from the analyzed data was $\mathrm{n}<30$ (S.P.S.S.18.0); the Wilcoxon test was used for comparison of intra-group differences and the Mann-Whitney $\mathrm{U}$ test was used to examine the differences between the two groups.

\section{Descriptive statistics of experimental and control groups}

As seen in Table 1, the experimental and control group consists of 15 students. The necessary balance between age and gender is provided.

Table 1. Descriptive statistics of experimental and control groups

\begin{tabular}{llllll}
\hline Control group & \multicolumn{5}{c}{ Experimental group } \\
\hline Gender & $\mathrm{N}$ & $\%$ & Gender & $\mathrm{N}$ & $\%$ \\
\hline Female & 9 & 60 & Female & 10 & 67 \\
Male & 6 & 40 & Male & 5 & 33 \\
Total & 15 & 100 & Total & 15 & 100 \\
\hline Age & & & Age & & 33 \\
\hline 18 & 5 & 33 & 18 & 5 & 40 \\
19 & 4 & 27 & 19 & 6 & 27 \\
20 & 6 & 40 & 20 & 4 & 100 \\
\hline Total & 15 & 100 & Total & 15 & \\
\hline
\end{tabular}

It is stated in the literature that studies with low number of test subjects do not have a normal distribution. Therefore non-parametric tests should be preferred (Siegal \& Castellan, 1988). The Man Witney U-test results from the Patience and (Perma) well-being scales after the application for students with low-patience levels who attended the patience training and for those who did not participate in such a program, are given in Table 2.

Accordingly, there was no significant difference in the pre-test results between patience and well-being scores of the control and experimental groups. When the rank average of Patience in everyday life ( $U=88,50, p>.05)$, İterpersonal patience $(U=112,00, p>.05)$, Patience in life difficulties $(U=93,50, p>.05)$, Positive emotion $(U=100,00, p>.05)$, Engagement (U=79,00, p>.05), Relations (U=107,50,p>.05), Meaning (U=112,50,p>.05), Accomplishment $(U=93,00, p>.05)$, Negative emotions $(U=75,50, p>.05)$, Health $(U=66,50, p>.05)$, Loneliness $(U=98,50, p>.05)$, Hapiness $(U=92,50, p>.05)$ is taken into account; it can be seen that the difference between the average of patience and well- being scores of experimental and control groups is not significant. This result suggests that the two groups have similar characteristics. 
Table 2. The pre-test comparison of Patience and (PERMA) well-being scores of the control and experimental groups

\begin{tabular}{|c|c|c|c|c|c|c|c|}
\hline & & & $\mathrm{n}$ & Mean rank & Rank sum & $\mathrm{u}$ & $\mathrm{p}$ \\
\hline & $\begin{array}{l}\text { Patience in } \\
\text { everyday life }\end{array}$ & Control group & 15 & 17,10 & 256,50 & 88,50 &, 32 \\
\hline \multirow{5}{*}{ 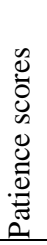 } & & Experimental group & 15 & 13,90 & 208,50 & & \\
\hline & İnterpersonal & Control group & 15 & 15,53 & 233,00 & 112,00 & ,98 \\
\hline & Patience & Experimental group & 15 & 15,47 & 232,00 & & \\
\hline & Patience in life & Control group & 15 & 14,23 & 213,50 & 93,50 & 42 \\
\hline & difficulties & Experimental group & 15 & 16,77 & 251,50 & & \\
\hline \multirow{18}{*}{ 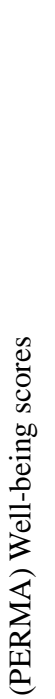 } & Positive emotions & Control group & 15 & 14,67 & 220,00 & 100,00 & 60 \\
\hline & & Experimental group & 15 & 16,33 & 245,00 & & \\
\hline & Engagement & Control group & 15 & 13,27 & 199,00 & 79,00 & , 16 \\
\hline & & Experimental group & 15 & 17,73 & 266,00 & & \\
\hline & Relations & Control group & 15 & 15,17 & 227,50 & 107,50 & ,84 \\
\hline & & Experimental group & 15 & 15,83 & 237,50 & & \\
\hline & Meaning & Control group & 15 & 15,50 & 232,50 & 112,50 & 1,0 \\
\hline & & Experimental group & 15 & 15,50 & 232,50 & & \\
\hline & Accomplishment & Control group & 15 & 14,20 & 213,00 & 93,00 & ,42 \\
\hline & & Experimental group & 15 & 16,80 & 252,00 & & \\
\hline & Negative emotions & Control group & 15 & 17,97 & 269,50 & 75,50 & , 12 \\
\hline & & Experimental group & 15 & 13,03 & 195,50 & & \\
\hline & Health & Control group & 15 & 18,57 & 278,50 & 66,50 & ,06 \\
\hline & & Experimental group & 15 & 12,43 & 186,50 & & \\
\hline & Loneliness & Control group & 15 & 16,43 & 246,50 & 98,50 & ,56 \\
\hline & & Experimental group & 15 & 14,57 & 218,50 & & \\
\hline & Happiness & Control group & 15 & 14,17 & 212,50 & 92,50 & ,41 \\
\hline & & Experimental group & 15 & 16,83 & 252,50 & & \\
\hline
\end{tabular}

In this study it was aimed to determine whether there is a relationship between patience and well-being levels among the university students participating in the patience education program and those who did not participate the program. Statistical analyzes of the collected data were made and the findings of these processes are shown in table 3 . findings obtained at the end of the study are given below: 
Table 3. Examination of pre-test and post-test data obtained from the patience and well-being scale of the control and experiment group by Wilcoxon Matched Pairs signed rank test

\begin{tabular}{|c|c|c|c|c|c|c|c|c|c|c|c|c|}
\hline \multicolumn{8}{|c|}{ Control group } & \multicolumn{5}{|c|}{ Experimental group } \\
\hline & & & $\mathrm{N}$ & Mean rank & Rank sum & $\mathrm{Z}$ & $\mathrm{p}$ & $\mathrm{N}$ & Mean rank & Rank sum & $\mathrm{Z}$ & $\mathrm{p}$ \\
\hline \multirow{9}{*}{ 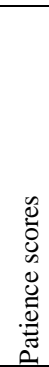 } & \multirow[t]{3}{*}{ Patience in everyday life } & Negative rank & 5 & 6,00 & 30,00 & \multirow[t]{3}{*}{,- 27} & \multirow[t]{3}{*}{,787 } & 2 & 1,50 & 3,00 & \multirow[t]{3}{*}{$-2,81$} & \multirow[t]{3}{*}{, 003} \\
\hline & & Positive rank & 6 & 6,00 & 36,00 & & & 10 & 7,50 & 75,00 & & \\
\hline & & Equal & 4 & & & & & 3 & & & & \\
\hline & İnterper- & Negative rank & 5 & 6,90 & 34,50 & \multirow[t]{3}{*}{,- 36} & \multirow[t]{3}{*}{, 722} & 2 & 2,00 & 4,00 & \multirow[t]{3}{*}{$-2,91$} & \multirow[t]{3}{*}{, 004} \\
\hline & \multirow{2}{*}{ sonal patience } & Positive rank & 7 & 6,21 & 43,50 & & & 11 & 7,91 & 87,00 & & \\
\hline & & Equal & 3 & & & & & 2 & & & & \\
\hline & \multirow[t]{3}{*}{ Patience in life difficulties } & Negative rank & 3 & 8,33 & 25,00 & \multirow[t]{3}{*}{,- 72} & \multirow[t]{3}{*}{,472 } & 2 & 2,50 & 5,00 & \multirow[t]{3}{*}{$-2,09$} & \multirow[t]{3}{*}{, 003} \\
\hline & & Positive rank & 8 & 5,13 & 41,00 & & & 7 & 5,71 & 40,00 & & \\
\hline & & Equal & 4 & & & & & 6 & & & & \\
\hline & \multirow[t]{3}{*}{ Positive emotions } & Negative rank & 8 & 6,75 & 54,00 & \multirow[t]{3}{*}{,- 09} & \multirow[t]{3}{*}{,924 } & 7 & 5,79 & 40,50 & \multirow[t]{3}{*}{$-1,11$} & \multirow[t]{3}{*}{, 265} \\
\hline & & Positive rank & 6 & 8,50 & 51,00 & & & 8 & 9,94 & 79,50 & & \\
\hline & & Equal & 1 & & & & & 0 & & & & \\
\hline & Engage- & Negative rank & 5 & 7,40 & 37,00 &,- 99 &, 323 & 10 & 7,45 & 74,50 &,- 83 & ,408 \\
\hline & ment & Positive rank & 9 & 7,56 & 68,00 & & & 5 & 9,10 & 45,50 & & \\
\hline & & Equal & 1 & & & & & 0 & & & & \\
\hline & Relations & Negative rank & 4 & 6,25 & 25,00 & $-1,73$ &, 082 & 6 & 6,08 & 36,50 & $-1,01$ &, 314 \\
\hline & & Positive rank & 10 & 8,00 & 80,00 & & & 8 & 8,56 & 68,50 & & \\
\hline & & Equal & 1 & & & & & 1 & & & & \\
\hline & Meaning & Negative rank & 4 & 5,50 & 22,00 &,- 56 &, 572 & 7 & 6,36 & 44,50 &,- 88 &, 377 \\
\hline & & Positive rank & 6 & 5,50 & 33,00 & & & 8 & 9,44 & 75,50 & & \\
\hline & & Equal & 5 & & & & & 0 & & & & \\
\hline & Accomp-lishment & Negative rank & 8 & 6,13 & 49,00 &,- 63 &, 529 & 3 & 5,67 & 17,00 & $-1,73$ & ,084 \\
\hline & & Positive rank & 7 & 10,14 & 71,00 & & & 9 & 6,78 & 61,00 & & \\
\hline & & Equal & 0 & & & & & 3 & & & & \\
\hline & Negative emotions & Negative rank & 6 & 5,83 & 35,00 & $-1,11$ & ,269 & 9 & 9,56 & 86,00 & $-1,48$ &, 139 \\
\hline & & Positive rank & 8 & 8,75 & 70,00 & & & 6 & 5,67 & 34,00 & & \\
\hline & & Equal & 1 & & & & & 0 & & & & \\
\hline & Health & Negative rank & 9 & 8,00 & 72,00 &,- 68 & ,494 & 5 & 5,40 & 27,00 & $-1,30$ & , 194 \\
\hline 迥 & & Positive rank & 6 & 8,00 & 48,00 & & & 8 & 8,00 & 64,00 & & \\
\hline $\begin{array}{l}\mathcal{D} \\
\text { on }\end{array}$ & & Equal & 0 & & & & & 2 & & & & \\
\hline. & Loneli-ness & Negative rank & 6 & 5,33 & 32,00 &,- 55 &, 580 & 6 & 8,42 & 50,50 &,- 35 &, 724 \\
\hline$\stackrel{0}{\stackrel{0}{\prime}}$ & & Positive rank & 6 & 7,67 & 46,00 & & & 7 & 5,79 & 40,50 & & \\
\hline$\stackrel{0}{3}$ & & Equal & 3 & & & & & 2 & & & & \\
\hline 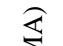 & Happi-ness & Negative rank & 6 & 4,33 & 26,00 &,- 43 & ,668 & 6 & 6,25 & 37,50 &,- 96 &, 340 \\
\hline$\sum$ & & Positive rank & 3 & 6,33 & 19,00 & & & 8 & 8,44 & 67,50 & & \\
\hline$\frac{1}{2}$ & & Equal & 6 & & & & & 1 & & & & \\
\hline
\end{tabular}

The Wicoxon signed rank test was applied to determine between which measurments the significant difference is found in the experimental group (Büyüköztürk, 2012). As a result of the analysis according to Table 3; the difference between the average scores from Patience in everyday life $(Z=--, 27, p>.05)$, Interpersonal patience $(Z=--, 36, p>.05)$ Patience in life difficulties $(Z=-, 72, p>.05)$ Positive emotion $(Z=-, 09, p>.05)$, Engagement $(Z=-.26, p>.05)$, Relations $(Z=-1,73$, $\mathrm{p}>.05)$, Meaning $(Z=-, 56, p>.05)$ Accomplishment $(Z=--, 63, p>.05)$, Negative emotions $(Z=-1,11, p>.05)$, Health $(Z=-, 68, p>.05)$, Loneliness $(Z=-, 55, p>.05)$ and Happiness $(Z=-, 43, p>.05)$ is not significant for the control group's pretest-posttest. This result shows that the control group did not change in terms of these properties during the application time. The difference between the mean scores of pretest-posttest for Patience in everyday life $(\mathrm{Z}=-2.81, \mathrm{p}$ $<.005)$, Interpersonal patience $(Z=-2.91, p<.005)$, Patience in life difficulties $(Z=209, p<.005)$ was significant in the experimental group. İt was seen that the difference between the average scores of Positive emotions $(Z=-3.59, p<.001)$, Engagement $(Z=-, 83, p<.001)$, Relations $(Z=-1,01 \mathrm{p}<.001))$, Meaning $(Z=-, 88, p<.001)$ Accomplishment $(Z=-1,73$, $\mathrm{p}<.001)$ Negative emotions $(Z=-1,48, p>.001)$, Health $(Z=-1,30, p>.001)$, Loneliness, $(Z=-, 35, p>.001)$ and Happiness $(Z=-, 96, p>.001)$ was not significant. In conclusion, at the end of the training there was no evidence that the patience values changed in the positive direction and there was also no change in the well-being levels. 
Table 4. Analysis with the Mann-Whitney U Test of data obtained from control and experiment group's post and trail tests of patience and (PERMA) well-being scale

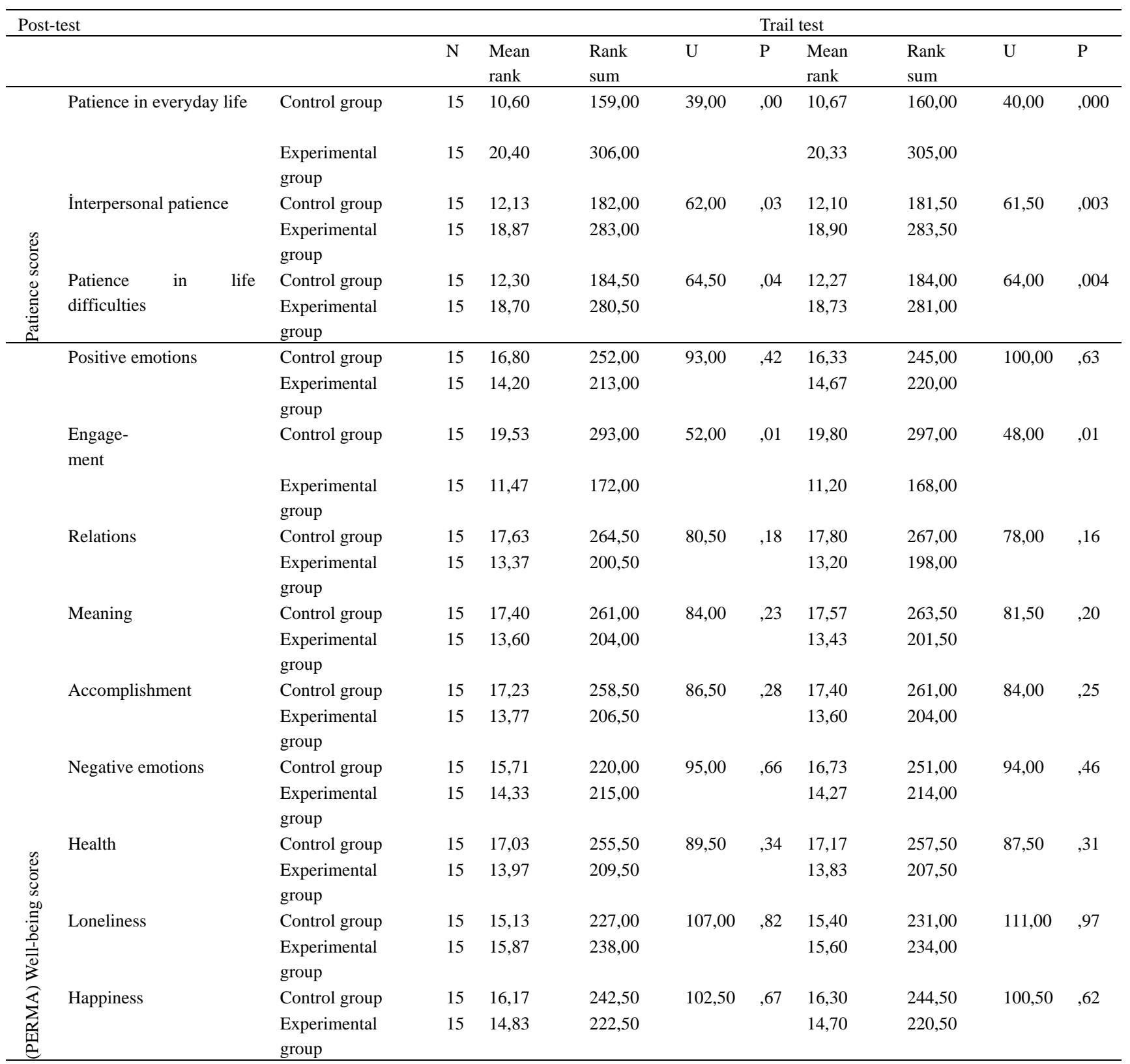

When the Mann-Whitney U test was applied to sub-dimensions of Patience and Well-being scales; the difference between all the sub-dimensions of the patience scale and the averages obtained from the post-test between in the experimental and control groups was found to be significant. The results for the sub-dimensions of the Well-being scale were not significant. When Table 4 is examined it can be seen that the difference between the Patience scale sub-dimension scores of Patience in everyday life $(U=168.5, p<.001)$, İnterpersonal patience $(U=127, p<.001)$, Patience in life difficulties $(\mathrm{U}=135, \mathrm{p}<.001)$ is significant for the post-test results of the control and experimental groups. There was no significant difference between the average scores of the Positive emotions $(\mathrm{U}=176, \mathrm{p}<.05)$, Engagement ( $U=162, p<.001)$, Relations ( $U=185, \mathrm{p}<.05)$, Meaning (U=159,p<.005), Accomplishment $(\mathrm{U}=165.5, \mathrm{p}<.005)$, Negative emotions $(\mathrm{U}=165.5, \mathrm{p}<.005)$, Health $(\mathrm{U}=192, \mathrm{p}<.05)$, Loneliness $(\mathrm{U}=192, \mathrm{p}<.05)$ and Happiness $(\mathrm{U}=192, \mathrm{p}<.05)$ sub-dimensions of the Well-being scale. When the Man-Whitney $U$ test was repeated for the sub-dimensions of patience and well-being scales, the difference between the mean values obtained from the follow-up test and the control group was significant in all sub-dimensions of the patience scale. However, the results for the sub-dimensions of the Well-being scale were not significant. The difference between the Patience in everyday life $(\mathrm{U}=168.5, \mathrm{p}<.001)$, İnterpersonal patience $(U=127, p<.001)$, Patience in life difficulties $(U=135, p<.001)$ sub-dimensions scores of the Patience scale post-test from the experimental and control groups were significant. When the average scores of the 
Positive emotions $(U=176, p<.05)$, Engagement $(U=162, p<.001)$, Relations $(U=185, p<.05)$, Meaning $(U=159, p<.005)$, Accomplishment $(U=165.5, p<.005)$, Negative emotions $(U=165.5, p<.005)$ Health $(U=192, p<.05)$ Loneliness $(U=192$, $\mathrm{p}<.05)$ and Happiness $(\mathrm{U}=192, \mathrm{p}<.05)$ sub-dimensions of the Well-being scales are examined it can be seen that the difference is significant.

\section{Discussion and Conclusions}

As a result of this research, it was seen that after patience training the patience levels of the subjects increased and there was no meaningful change in the level of well-being. Therefore, when the Man-Whitney $U$ test was applied to the sub-dimensions of patience and well-being, the difference between the averages obtained from the post-test between the experimental and control groups in all sub-dimensions of the patience scale was found to be significant. There were no significant results for the sub-dimensions of the Well-being scale, except the "occupation" sub-dimension. The same finding was also valid for the trail test. While the score differences of all the sub-dimensions of patience were significant, the difference between the scores of all the sub-dimensions of the Well-being scale was not significant. When we review the literature, some experimental studies have shown similar results with our study. There is a relationship between patience and well-being in the part of the same studies conducted by the screening method (Schnitker \& Emmons 2007; Schnitker, 2010). Again, in other studies conducted with the scanning model, findings in the opposite direction were seen (Peterson \& Seligman, 2001; Ryan \& Deci, 2000; Kahneman, Diener \& Schwartz, 1999; Ryff \& Singer, 1988; Campton Smith, Cornish \& Qualls, 1996; Ryan \& Deci, 2001; Diener, Sapyta, \& Suh, 1998; Sheldon, Ryan, Deci \& Kasser, 2004).

Schnitker \& Emmons (2007) found a positive relationship between patience and well-being. Peterson \& Seligman (2001) stated that patience is associated with positive social characteristics and virtues, and that patient individuals exhibit a more empathetic and more vigorous attitude. İt was seen in an experimental study of Schnitker, 2010 that there is a positive relation between patience and between optimism and hope. Ryan \& Deci (2000) argue that patience has improved eudamonic well-being. In Schnitker \& Emmons (2007) study, the relationship between patience and other well-being indicators (depression, life satisfaction, loneliness and self-perception) was not found significant. According to Kahneman, Diener \& Schwartz (1999), when looking at the relationship between eudamonic well-being and patience; there was an increase in eudamonic well-being, which showed that the patience do increase satisfaction with positive emotions. Ryff \& Singer (1988) found that there is an association between patience and well-being in his study. Campton Smith, Cornish \& Qualls (1996) found a moderate relationship between patience, happiness and well-being in their study. Ryan \& Deci (2001) suggested that patience affects hedonic and eudemonic well-being. Diener, Sapyta, \& Suh (1998) argued that hedonic well-being is indirectly influenced by increasing patience, positive emotions and life satisfaction, making it easier to reach the target. Sheldon, Ryan, Deci, and Kasser (2004) found in their study that the target content and reason can change well-being. Patience should be considered as a coping tool for the delay of goals or potential failure. Schnitker (2010) found a very high correlation between patience and well-being. Even after personality check; it was seen that patience can effect depression, life satisfaction and happiness. After the Patient Training it was concluded in experimental work, that with the patience training, depression was alleviated, but life satisfaction or well-being did not change significantly. However, goal satisfaction is mediated through the relationship between patience and well-being over time. According to Schnitker \& Emmons (2007), patience is found to have a positive correlation with subjective well-being, positive coping, virtues and being successfully.

According to the findings of the study; the applied patience training program increased the patience level of the individuals. However, it has been found that there is no effect on the level of well-being. It may be advisable to design new studies with additional sesions and similar patience training events applied in this research and prepared by the researchers in order to raise also the well-being leveles of the "patience education training".

\section{References}

Butler, J., \& Kern, M. L. (2016). The PERMA-Profiler: A brief multidimensional measure of flourishing. International Journal of Wellbeing, 6(3), 1-48. https://doi.org/10.5502/ijw.v6i3.526

Büyüköztürk, Ş. (2012). Sosyal bilimler için veri analizi el kitabı. Ankara: Pegem Akademi

Compton, W. C., Smith, M. L., Cornish, K. A., \& Qualls, D. L. (1996). Factor structure of mental health measures. Journal of Personality and Social Psychology, 71(2), 406-413. https://doi.org/10.1037/0022-3514.71.2.406

Csikszentmihalyi, M. (1990). Flow: The psychology of optimal experience. New York, NY: Harper and Row.

Deci, E. L., \& Ryan, R. M. (2002). Handbook of self-determination research. Rochester: The University of Rochester Press

Diener, E., Sapyta, J. J., \& Suh, E. (1998). Subjective wellbeing is essential to well-being. Psychological Inquiry, 9, 33-37. https://doi.org/10.1207/s15327965pli0901_3 
Eliüşük, A. (2016). Perma Adaptation Of Well Being Measure To Turkish: Work Of Validity And Reliability, 28 June 2016, 3rd Teaching \& Education Conference, Barcelona

Eliüşük, A., \& Arslan, C. (2016). Sabır Ölçeğinin Türkçe'ye Uyarlanması: Geçerlilik ve Güvenirlik Çalışmaları. Değerler Eğitimi Dergisi, 14(31), 67-86. Retrieved from http://dergipark.gov.tr/ded/issue/29165/312321

Forgeard, M. J. C., Jayawickreme, E., Kern, M. L., \& Seligman, M. E. P. (2011). Doing the right thing: Measuring well-being for public policy. International Journal of Wellbeing, 1, 79-106.

Huppert, F. A. (2009). Psychological well-being: Evidence regarding its causes and consequences. Applied Psychology: Health and Well-being, 1, 137-164. https://doi.org/10.1111/j.1758-0854.2009.01008.x

Kahneman, D., Diener, E., \& Schwarz, N. (Eds.). (1999). Well-being: The foundations of hedonic psychology. New York: Russell Sage Foundation.

McCullough, M. E., Tsang, J., \& Emmons, R. A. (2004). Gratitude in intermediate affective terrain: Links of grateful moods to individual differences and daily emotional experience. Journal of Personality and Social Psychology, 86, 295-309. https://doi.org/10.1037/0022-3514.86.2.295

Mehrabian, A. (1999). Manual for the Revised Achieving Tendency (MACH) and Disciplined Goal Orientation (CGO) Scales. Monterey, California: Alta Mesa

Parry, M., \& Norling, (2009). Innovation is patience a virtue, Research Technology Management Industrial Research Institute. Inc. 0895-6308/09

Peterson, C., \& Seligman, M. E. P. (2004). Character strengths and virtues: A classification and handbook. New York: Oxford University Press/Washington, DC: American Psychological Association

Ryan, R. M., \& Deci, E. L. (2000). Self-determination theory and the facilitation of intrinsic motivation, social development, and well-being. American Psychologist, 55(1), 68-78. https://doi.org/10.1037/0003-066X.55.1.68

Ryan, R. M., \& Deci, E. L. (2001). To be happy or to be self-fulfilled: A review of research on hedonic and eudaimonic wellbeing. In S. Fiske (Ed.), Annual Review of Psychology (Vol. 52; 141-166). Palo Alto, CA: Annual Reviews/Inc.

Ryff \& Singer (1998). Ryff CD, Singer B. The contours of positive human health. Psychological Inquiry, 9, 2-28.

Ryff (1989) Ryff CD. Happiness is everything, or is it? Explorations on the meaning of psychological well-being. Journal of Personality and Social Psychology, 57, 1069-1081. https://doi.org/10.1037/0022-3514.57.6.1069

Schnitker, S. A. (2010). An examination of patience and well-being. (Dissertation Doctor of Philosophy in Psychology). University of California: Davis.

Schnitker, S. A. (2012). An examination of patience and well-being, The Journal of Positive Psychology: Dedicated to furthering research and promoting good practice, 7(4), 263-280.

Schnitker, S. A., \& Emmons, R. A. (2007). Patience as a virtue: Religious and psychological perspectives. Research in the Social Scientific Study of Religion, 18, 177-207. https://doi.org/10.1163/ej.9789004158511.i-301.69

Seligman, M. E. P. (2002). Authentic happiness. New York: Free Press.

Seligman, M. E. P. (2011). Flourish: A visionary new understanding of happiness and well-being. New York, NY: Free Press.

Sheldon, K. M., Ryan, R. M., Deci, E. L., \& Kasser, T. (2004). The independent effects of goal contents and motives on well-being: It's both what you pursue and why you pursue it. Personality and Social Psychology Bulletin, 30, 475-486. https://doi.org/10.1177/0146167203261883

Siegal, S., \& Castellan, N. J. (1988). Nonparametric statistics for the behavioral sciences (2nd ed.). New York, NY: McGraw-Hill.

Telef, B. B. (2013). Psikolojik İyi Oluş Ölçeği: Türkçeye uyarlama, geçerlik ve güvenirlik çalışması. Hacettepe Üniversitesi Eğitim Fakültesi Dergisi, 28(3), 374-384.

Tuzgöl-Dost, M. (2005). Öznel İyi Oluş Ölçeği'nin geliştirilmesi: Geçerlik ve güvenirlik çalışması. Türk Psikolojik Danışma ve Rehberlik Dergisi, 3(23), 103-111.

\section{Copyrights}

Copyright for this article is retained by the author(s), with first publication rights granted to the journal.

This is an open-access article distributed under the terms and conditions of the Creative Commons Attribution license which permits unrestricted use, distribution, and reproduction in any medium, provided the original work is properly cited. 